\title{
Nutrient-induced activation of trehalase in nutrient-starved cells of the yeast Saccharomyces cerevisiae: cAMP is not involved as second messenger
}

\author{
Kumara Hirimburegama, $†$ Peter Durnez, Johan Keleman, Els Oris, Rudy Vergauwen, \\ Hubert Mergelsberg and Johan M. TheVElein*
}

Laboratorium voor Moleculaire Celbiologie, Katholieke Universiteit te Leuven, Kardinaal Mercierlaan 92, B-3001

Leuven-Heverlee, Flanders, Belgium.

(Received 8 January 1992; revised 23 June 1992; accepted 10 July 1992)

\begin{abstract}
Starvation of Saccharomyces cerevisiae cells for specific nutrients such as nitrogen, phosphate or sulphate causes arrest in the $G_{1}$ phase of the cell cycle at a specific point called 'start'. Re-addition of different nitrogen sources, phosphate or sulphate to such starved cells causes activation of trehalase within a few minutes. Nitrogen-sourceand sulphate-induced activation of trehalase were not associated with any change in the cAMP level, but in the case of phosphate there was a small transient increase. When nitrogen-source-activated trehalase was isolated by immuno-affinity chromatography from crude extracts, the purified enzyme showed the same activity profile as in the original crude extracts, indicating that post-translational modification is responsible for the activation. In the yeast mutants $c d c 25-5$ and $c d c 35-10$, which are temperature sensitive for cAMP synthesis, incubation at the restrictive temperature lowered but did not prevent nitrogen-, phosphate- or sulphate-induced activation of trehalase. Since under these conditions the cAMP level in the cells is very low, it is unlikely that cAMP acts as a second messenger in this nutrient-induced effect. Nitrogen-source-induced activation of trehalase requires the presence of glucose at a concentration similar to that able to stimulate the RAS-adenylate cyclase pathway. This indicates that the same glucose-sensing system might be involved in both phenomena. Nitrogen-starved cells fractionated according to cell size all showed nitrogen-source-induced activation of trehalase to the same extent, indicating that the nitrogen-induced signalling pathway involved is not dependent on the well-known cell size requirement for progression over the start point of the cell cycle.
\end{abstract}

\section{Introduction}

Starvation of Saccharomyces cerevisiae cells for specific nutrients such as nitrogen, phosphate or sulphate causes arrest in the $G_{1}$ phase of the cell cycle at a specific point called 'start'. The start point contains two sites: the nutrient-starvation site and a subsequent pheromoneinduced arrest site (Pringle \& Hartwell, 1981). In recent years evidence has been obtained that cAMP is involved in the progression over the nutrient-starvation site of start. When temperature-sensitive mutants in cAMP synthesis are shifted to the restrictive temperature they arrest at this site in start, while mutants with enhanced cAMP levels or protein kinase A activity were reported

* Author for correspondence. Tel. 16220931 ; fax 16221855.

† Present address: Department of Botany, University of Colombo, PO Box 1490, Colombo 3, Sri Lanka. not to arrest at this point under starvation conditions (recent reviews: Gibbs \& Marshall, 1989; Broach \& Deschenes, 1990).

In yeast, the RAS proteins regulate adenylate cyclase activity in a way similar to the $\mathrm{G}_{\mathrm{s}}$ proteins of mammalian adenylate cyclase (Gibbs \& Marshall, 1989). Several components of the RAS-adenylate cyclase pathway have been identified, including CDC25, which is required for activation of the RAS proteins, the RAS-GTPaseactivating proteins IRA1 and IRA2, RPI1, a positive effector of both $I R A$ gene products and the $S R V 2$ gene product (or 'CAP'), a subunit of adenylate cyclase. The genes coding for adenylate cyclase $(C Y R I=C D C 35)$, cAMP phosphodiesterase (PDE1,PDE2) and the catalytic $(T P K 1, T P K 2, T P K 3)$ and regulatory $(B C Y 1)$ subunits of CAMP-dependent protein kinase have also been cloned and characterized (recent reviews: Gibbs \& Marshall, 1989; Broach \& Deschenes, 1990). Despite the 
identification of many components of the RAS-cAMP pathway, very little progress has been made in understanding the signalling function of the pathway, especially in relation to progression over the start point of the cell cycle. We have shown that the CDC25 and RAS proteins function as signal transmitters in a pathway responsible for activation of adenylate cyclase by fermentable sugar and by intracellular acidification (Mbonyi et al., 1988; Van Aelst et al., 1990, 1991). The RAS activation pathway that is induced by fermentable sugar is, however, glucose-repressible and is not required for progression over the start point of the cell cycle. We have proposed, therefore, that in repressed cells a nitrogen signalling pathway is the true pathway triggering progression over the start point of the yeast cell cycle (Thevelein, 1991).

Nitrogen sources are able to cause, in the presence of glucose, rapid and drastic activation of trehalase, an enzyme generally considered in yeast to be regulated by cAMP-dependent protein phosphorylation (review: Thevelein, 1988). However, we have shown previously that in derepressed diploid yeast cells, nitrogen-sourceinduced activation of trehalase under a variety of conditions was never associated with a cAMP increase, as opposed to glucose-induced activation of trehalase in such derepressed cells. The protein synthesis inhibitors cycloheximide and anisomycin did not inhibit the nitrogen effect, but caused, in the absence of nitrogen, an activation of trehalase very similar to but somewhat slower than that observed with the nitrogen sources (Thevelein \& Beullens, 1985). Activation by nitrogen sources and lack of correlation with cAMP levels has also been demonstrated for other enzymes generally considered to be regulated by cAMP-dependent protein phosphorylation: phosphofructokinase 2, glycogen synthase and phosphorylase (François et al., 1988). In the present paper we have made use of temperature-sensitive mutants in cAMP synthesis to study in a more profound way the possible involvement of cAMP as second messenger for nitrogen-source-induced activation of trehalase in nitrogen-starved haploid yeast cells.

Previous work has shown that activation of trehalase by both nitrogen sources and protein synthesis inhibitors requires the presence of glucose (Thevelein \& Beullens, 1985 ; François et al., 1988). Activation by glucose of the
RAS-adenylate cyclase pathway requires relatively high concentrations of glucose: the concentration required for half-maximal stimulation is about $20 \mathrm{~mm}$ (Beullens et al., 1988). To see whether glucose might be sensed by the same system in both cases, we determined also the glucose-concentration requirement for nitrogen-sourceinduced activation of trehalase.

\section{Methods}

Yeast strains. Saccharomyces cerevisiae strains used in this study are shown in Table 1.

Culture and starvation conditions. Strain Y55 was grown on potassium acetate medium as described previously (Thevelein \& Beullens, 1985). For the nitrogen-, phosphate- and sulphate-starvation experiments in Fig. 2 the minimal synthetic medium described by Johnston et al. (1977) was used, except that the glucose concentration was adjusted to $3 \%(w / v)$. Starvation was carried out for $3 \mathrm{~d}$ in the same medium lacking, respectively, nitrogen, phosphate or sulphate. For subsequent nitrogen-starvation experiments the cells were grown in rich medium (YPD, containing 4\%, w/v, glucose) or for strain OL97-1-11B + pRA$S 2^{\text {ile } 152}$, minimal medium (SDGlucose - uracil containing $4 \%$ glucose) (Sherman et al., 1986), and starvation was carried out for $24 \mathrm{~h}$ at a cell density of 5-10 mg cells ml-1 in a medium containing $4 \%$ glucose and $0.67 \%$ Difco Yeast Nitrogen Base without amino acids and ammonium sulphate. In all cases, great care was taken that the glucose concentration in the cultures always remained high, so that the cells were kept in a repressed state.

Incubation and extraction conditions. Nitrogen-source-induced reactivation of trehalase after glucose-induced activation in cells of the Y 55 strain was done as described previously (Thevelein \& Beullens, 1985). In the experiments with starved cells, the cells were resuspended in fresh starvation medium before the compound for which they had been starved was added again. In the experiment of Fig. 8, resuspension was in proline-containing growth medium. Sampling of the cells and preparation of crude extracts were done as described previously (Thevelein \& Beullens, 1985).

Immuno-affinity isolation of trehalase. Monoclonal antibodies raised against a trehalase preparation purified in our laboratory were provided by Gist-Brocades. The antibodies were purified from ascites fluid by FPLC on a Protein A Superose column (Pharmacia-LKB). The antibodies were coupled to agarose gel beads with the Bio-Rad Affi-Gel Hz Immunoaffinity kit.

Determination of trehalase activity, cAMP and trehalose levels. Trehalase activity in crude extracts was determined as described previously (Thevelein et al., 1983). The activity of immuno-affinityisolated trehalase was determined by incubation of identical samples of gel beads with substrate solution for $10 \mathrm{~min}$ followed by determination of the liberated glucose as described also by Thevelein et al. (1983) cAMP levels were determined as described by Thevelein et al. (1987). Trehalose was determined according to Trevelyan \& Harrison (1956).

Table 1. Saccharomyces cerevisiae strains used in this work

\begin{tabular}{|c|c|c|}
\hline Strain & Genotype & Source (and reference) \\
\hline Y55 & $\mathbf{a} / \alpha$ homothallic & Laboratory stock \\
\hline SP1 & $M A T \mathbf{a}$ his3 leu2 ura3 trpl ade8 canl & M. Wigler (Toda et al., 1985) \\
\hline PD6517 & MATa leu2 trpl ade8 cdc35-10 & Our laboratory (Becher dos Passos et al., 1992) \\
\hline OL86 & $M A T \alpha$ cdc25-5 ade 2 leu 2 trp1 & M. Jacquet (Camonis et al., 1986) \\
\hline OL97-1-11B + pRAS2 ile152 & $M A T \alpha$ cdc25-5 leu2 ura3 his3 his $7+\mathrm{p} R A S 2^{\text {ile } 152}$ & M. Jacquet (Camonis \& Jacquet, 1988) \\
\hline
\end{tabular}


Cell fractionation by centrifugal elutriation. Cells were fractionated according to size in a Beckman $J-6 M / E$ centrifuge equipped for elutriation with a JE-5.0 rotor. Centrifugation was carried out at 3000 r.p.m. and $4{ }^{\circ} \mathrm{C} ; 10 \mathrm{~g}$ (wet wt) cells suspended in ice-cold distilled water were loaded into the rotor chamber at a pump rate of $23 \mathrm{ml} \mathrm{min}-1$. Consecutive cell fractions were collected in 1 litre volumes by increasing the pump speed from $23 \mathrm{ml} \mathrm{min}^{-1}$ in several steps to $220 \mathrm{ml} \mathrm{min}^{-1}$, resulting in an approximate increase in cell diameter of about $1 \mu \mathrm{m}$ per fraction. The cells in the different fractions were collected by filtration on Whatman glass-fibre filters $(45 \mathrm{~mm}$ diam.).

Reproducibility of results. All experiments were repeated at least twice with consistent results. Representative results are shown.

\section{Results}

We have shown previously that addition of a nitrogen source causes rapid reactivation of trehalase in derepressed yeast cells of the diploid strain Y55 in which trehalase was first transiently activated by addition of 100 mM-glucose (Thevelein \& Beullens, 1985). No definite proof is available yet that this nitrogen-sourceinduced activation of trehalase is mediated by phosphorylation. However, the isolation of trehalase with monoclonal antibodies raised against the purified enzyme, and which are able to bind the enzyme in such a way that it remains active, strongly suggests that nitrogen-source-induced activation of trehalase is due to post-translational modification (Fig. 1). When the enzyme was bound to gel beads by means of the monoclonal antibodies, the activity profile of the enzyme on the beads as a function of time after nitrogen addition followed exactly that of the original cell extracts from which the enzyme was isolated (Fig. 1). Taken together with previous results that nitrogen-source-induced activation of trehalase is not inhibited by cycloheximide, these results strongly point to post-translational modification and most probably phosphorylation, as being responsible for the activation. Other experiments have shown that trehalase activated by nitrogen sources in vivo can be deactivated by alkaline phosphatase treatment in vitro (unpublished results). On the other hand, it has not been possible to demonstrate phosphorylation in vivo by measuring $\left[{ }^{32} \mathrm{P}\right]$ phosphate incorporation. This might be due to proteolytic stabilization of the activated phosphorylated form of the enzyme. In addition elution of immuno-affinity-isolated trehalase from the gel beads followed by SDS-electrophoresis invariably gives a polypeptide pattern indicating strong proteolytic attack (C. De Greef, unpublished results).

Since the phenomenon of transient glucose-induced activation of trehalase followed shortly afterwards by nitrogen-source-induced reactivation of trehalase was poorly reproducible in haploid laboratory strains, we extended the incubation period in the presence of glucose to $24 \mathrm{~h}$ (in a synthetic medium) so that the cells were not starved for nitrogen and completely arrested in $\mathrm{G}_{0}$ as round unbudded cells. As can be observed in Fig. 2(a,b), addition of $10 \mathrm{~mm}$-ammonium sulphate $(+$ the essential amino acids for which the strain is auxotrophic at the same concentrations as in the growth medium) to such starved cells caused rapid activation of trehalase and also mobilization of the trehalose that is accumulated in starved yeast cells (Lillie \& Pringle, 1980). Addition of phosphate and to a lesser extent sulphate to, respectively, phosphate- and sulphate-starved cells also caused activation of trehalase (Fig. $2 d, g$ ), followed by a relatively slow mobilization of trehalose (Fig. $2 e, h$ ). Nitrogen- and sulphate-induced activation of trehalase were not associated with a typical transient increase in the cAMP level (Fig. $2 c, i$ ), as had been observed previously for glucoseinduced activation of trehalase in glucose-starved cells (Van der Plaat, 1974; Thevelein, 1984a; Thevelein \& Beullens, 1985). In the case of phosphate-induced activation of trehalase a small, but reproducible transient increase in the cAMP level was observed (Fig. $2 f$ ). The experiments shown in Fig. 2 were carried out with the cdc25-5 mutant, which is temperature sensitive for cAMP synthesis (Camonis et al., 1986; Van Aelst et al., 1991). Incubation of the cells under the same conditions at the restrictive temperature lowered to some extent, but did not prevent nitrogen-, phosphate- or sulphateinduced activation of trehalase. Under these conditions,

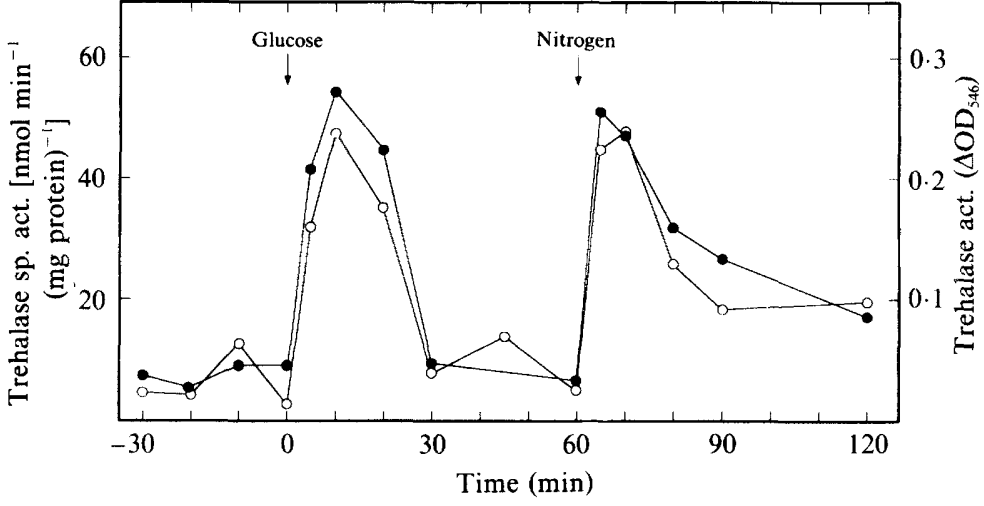

Fig. 1. Glucose-induced activation of trehalase and nitrogen-source $\left(\mathrm{NH}_{4} \mathrm{Cl}\right)$-induced reactivation of trehalase in derepressed diploid cells of strain Y55. - Activity of trehalase in crude cell extracts. $O$, Activity of trehalase isolated by immuno-affinity chromatography from the same crude cell extracts. Glucose was added at a concentration of $100 \mathrm{mM}$, $\mathrm{NH}_{4} \mathrm{Cl}$ at $10 \mathrm{~mm}$. 

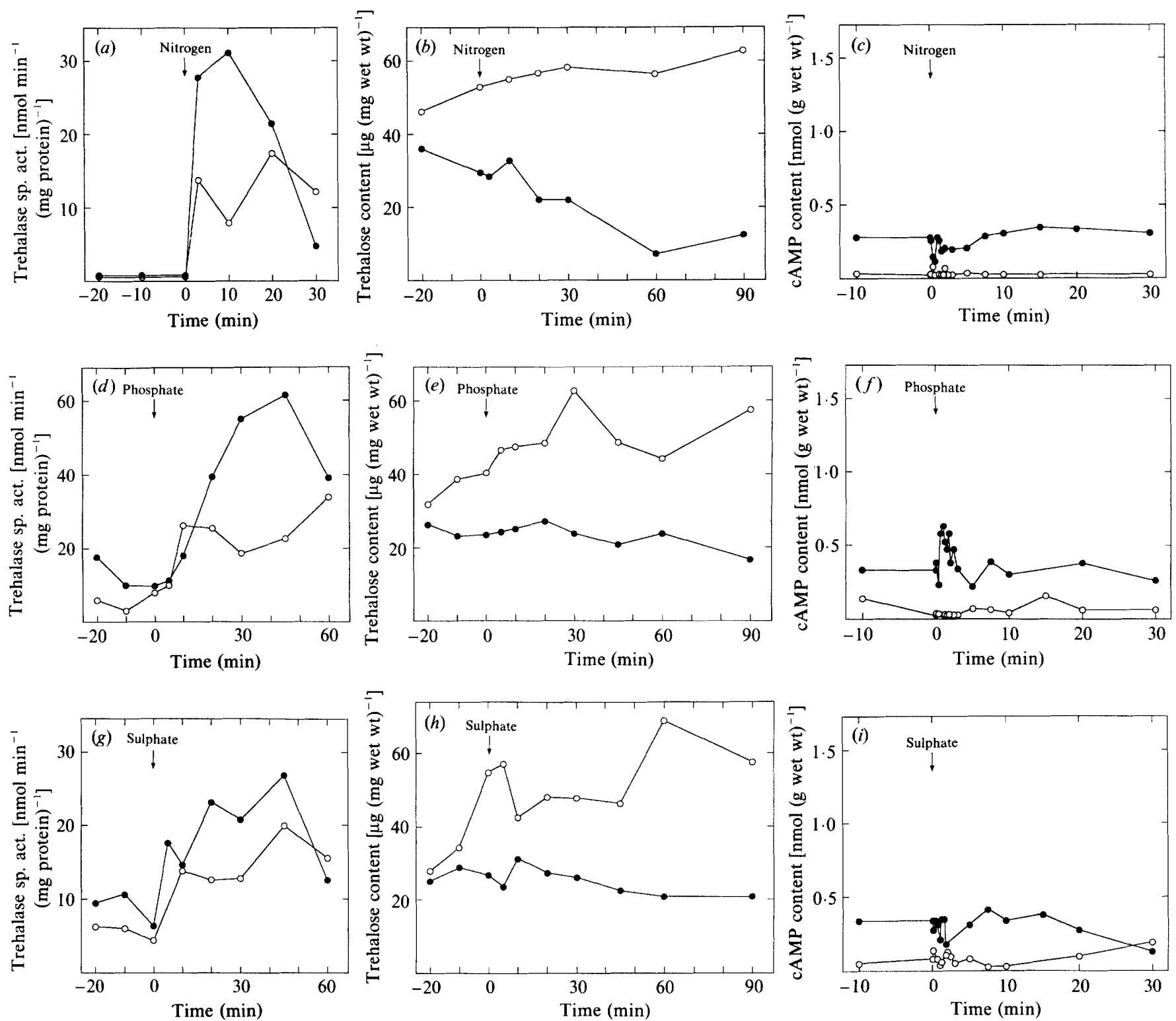

Fig. 2. Trehalase activity $(a, d, g)$, cAMP $(e, f, i)$ and trehalose $(b, e, h)$ levels upon re-addition of a nitrogen source $[a-c$; $\left(\mathrm{NH}_{4}\right)_{2} \mathrm{SO}_{4}+$ essential amino acids], phosphate $(d-f)$ or sulphate $(g-i)$ in glucose-containing medium to respectively, nitrogen-, phosphate- and sulphate-starved cells of the $c d c 25-5$ strain at the permissive temperature $\left(22^{\circ} \mathrm{C}, 0\right)$ and the restrictive temperature $\left(37^{\circ} \mathrm{C}, \mathrm{O}\right)$. Starvation and re-addition were carried out in synthetic medium.

the cAMP level remained throughout at a level much below that present at the permissive temperature before addition of the lacking nutrient.

In subsequent experiments, the synthetic nitrogen starvation medium was replaced by a medium containing Difco Yeast Nitrogen Base without amino acids and without $\left(\mathrm{NH}_{4}\right)_{2} \mathrm{SO}_{4}$. In addition, $10 \mathrm{~mm}-\left(\mathrm{NH}_{4}\right)_{2} \mathrm{SO}_{4}$ was replaced as activating agent by $10 \mathrm{~mm}$-asparagine $(+$ the essential amino acids for which the strain is auxotrophic at the same concentrations as in the growth medium). These changes resulted in a higher level of nitrogensource-induced trehalase activation that was also not associated with any significant increase in the cAMP level (Fig. 3). Further experiments under these conditions with the temperature-sensitive strains for cAMP synthesis, $c d c 25-5$ and $c d c 35-10$ (encoding adenylate cyclase) confirmed that it is very unlikely that cAMP acts as a second messenger for nitrogen-source-induced signalling (Figs 4 and 5). However, in all experiments using temperature-sensitive mutants for cAMP synthesis the extent of nitrogen-source-induced activation of trehalase at the restrictive temperature was lowered compared to that observed at the same temperature $\left(37^{\circ} \mathrm{C}\right)$ in wild-type cells. In the latter, activation at $37^{\circ} \mathrm{C}$ 


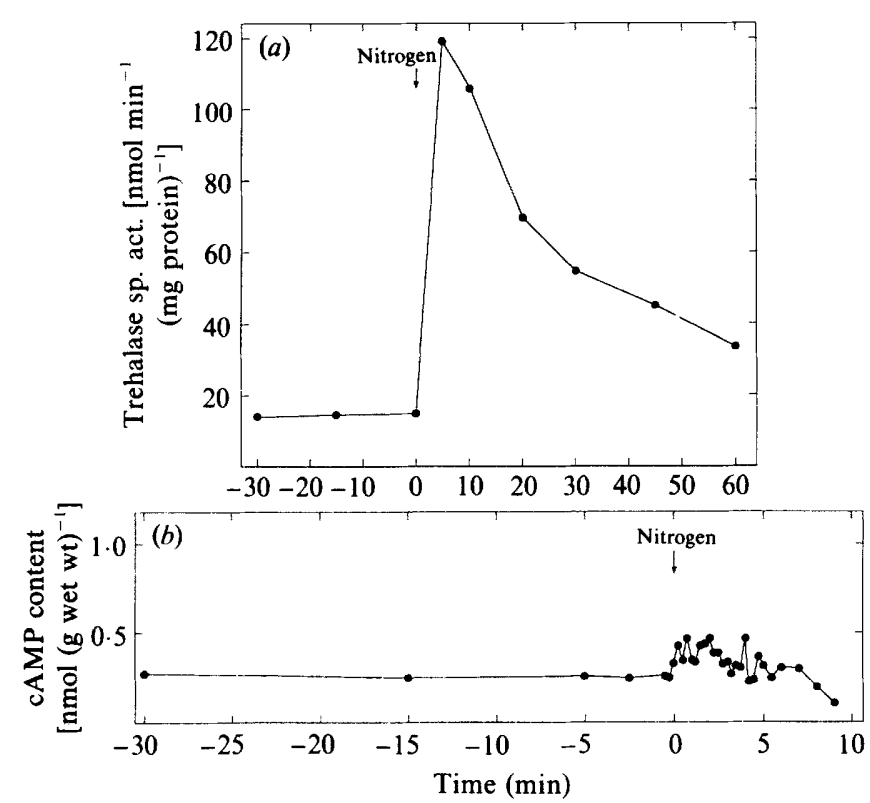

Fig. 3. Trehalase activity $(a)$ and cAMP level $(b)$ upon re-addition of a nitrogen source (10 mM-asparagine + the essential amino acids) to nitrogen-starved cells of the wild-type strain SP1. Starvation and readdition were carried out in medium containing glucose and Yeast Nitrogen Base without amino acids and without $\left(\mathrm{NH}_{4}\right)_{2} \mathrm{SO}_{4}$.
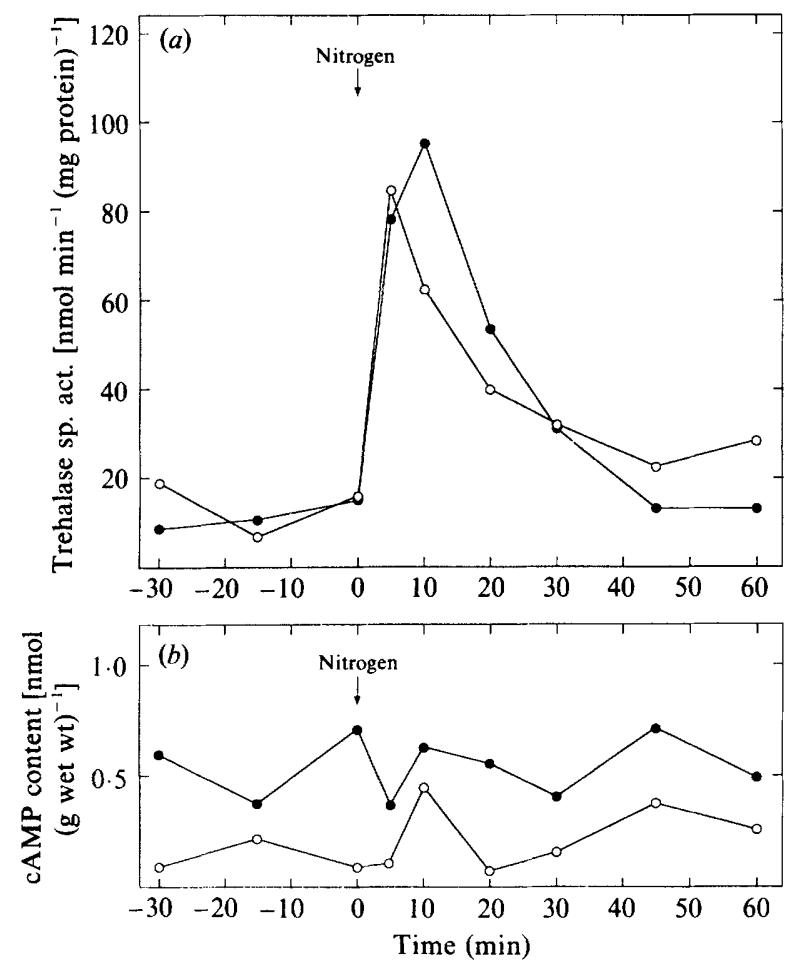

Fig. 4. Trehalase activity $(a)$ and cAMP level $(b)$ upon re-addition of a nitrogen source (10 mM-asparagine + the essential amino acids) to nitrogen-starved cells of the $c d c 35-10$ strain at the permissive temperature $\left(24^{\circ} \mathrm{C}, 0\right)$ and the restrictive temperature $\left(37^{\circ} \mathrm{C}, \mathrm{O}\right)$. Starvation and re-addition were carried out in medium containing glucose and Yeast Nitrogen Base without amino acids and without $\left(\mathrm{NH}_{4}\right)_{2} \mathrm{SO}_{4}$. was always much higher than at $24^{\circ} \mathrm{C}$ (Fig. 5). The same reduction in the extent of activation was also observed in a $c d c 25-5$ strain transformed with the plasmid pRAS2 ile152 (Fig. 6a). This strain is not temperature sensitive. The presence of the RAS2 $2^{\text {ile } 152}$ oncogene rescues the temperature-sensitive character because it allows cAMP synthesis without CDC25 function (Camonis \& Jacquet, 1988). The cAMP level at $37^{\circ} \mathrm{C}$, however, still remains below that measured at $22^{\circ} \mathrm{C}$ (Fig. 6b).

Investigation of nitrogen-source-induced activation of trehalase at different glucose concentrations showed that half-maximal activation occurred at about $20 \mathrm{~mm}$ glucose (Fig. 7). This is the same concentration as that causing half-maximal stimulation of the RAS-adenylate cyclase pathway (Beullens et al., 1988).

Growth of wild-type yeast cells on a medium containing a poor nitrogen source such as proline results in slow growth which is characterized by an extended $G_{1}$ phase (Pringle \& Hartwell, 1981). Slow-growing yeast cells in general are known to contain much higher amounts of trehalose than rapidly growing cells (Thevelein, 1984b). Fig. 8 shows that addition of a good nitrogen source, asparagine, to cells of the wild-type strain Y55 (diploid and prototrophic) growing on proline causes an immediate activation of trehalase in a way very similar to that observed during growth induction in nitrogen-starved cells. This indicates that in yeast rapid trehalase activation is a very general phenomenon associated not only with growth induction but also with growth stimulation.

Yeast cells have to reach a critical cell size before they can start a new cell cycle (Pringle \& Hartwell, 1981). To investigate whether this critical cell size is also required for the nitrogen-source-induced activation of trehalase associated with growth induction in nitrogen-starved cells, we fractionated nitrogen-starved cells according to size by centrifugal elutriation. The different size classes had cell diameters of approximately 5-6, 6-7, 8-9 and 9$10 \mu \mathrm{m}$. In agreement with a previous report by Johnston et al. (1977), the two smallest fractions, i.e. the cells with diameters of 5-6 and 6-7 $\mu \mathrm{m}$, started forming buds when resuspended in complete medium about $30 \mathrm{~min}$ later than the cells from the two largest fractions. Despite this, nitrogen-source-induced activation of trehalase was very similar in all four fractions (Fig. 9), indicating that a definite, critical cell size is not required for the nitrogen effect.

\section{Discussion}

The study of the molecular mechanisms by which nutrients control progression over the start point of the cell cycle is complicated by the widespread effects of 


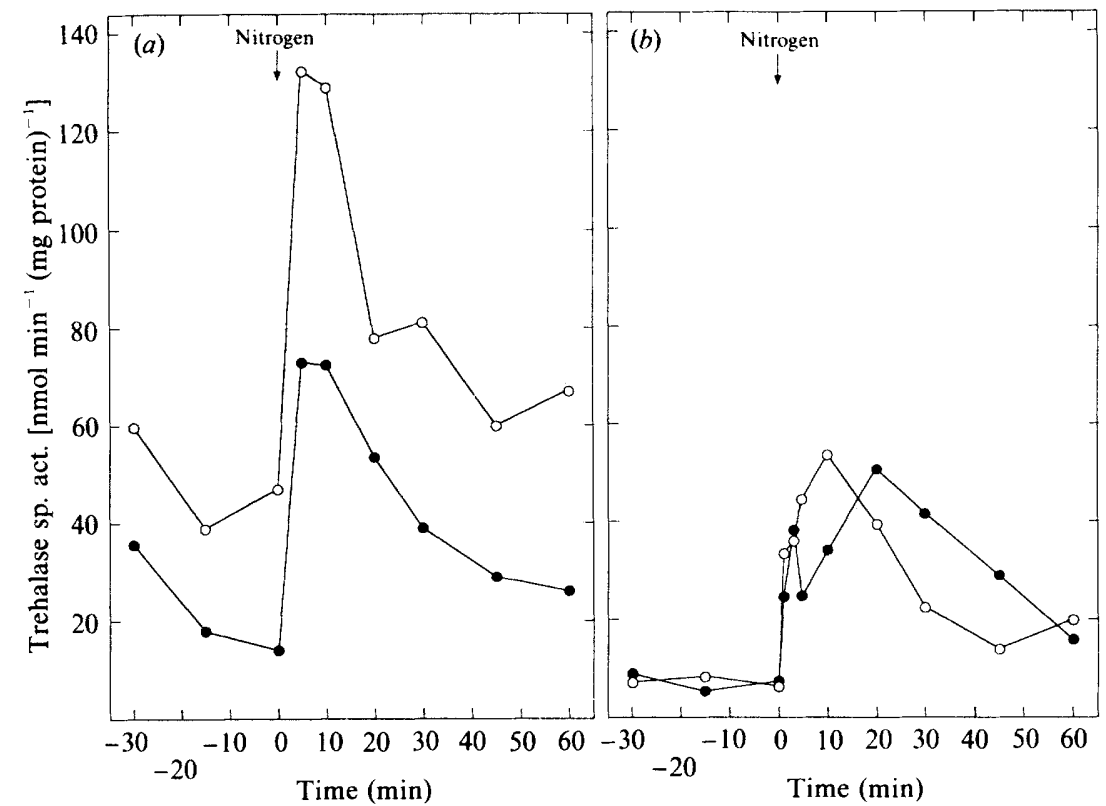

Fig. 5. Effect of temperature on nitrogen-source (10 mM-asparagine + the essential amino acids)-induced activation of trehalase in the wild-type strain SP1 (a) and in the $c d c 25-5$ mutant $(b) .0,24^{\circ} \mathrm{C}$; $\mathrm{O}$, $37^{\circ} \mathrm{C}$. Starvation and re-addition were carried out in medium containing glucose and Yeast Nitrogen Base without amino acids and without $\left(\mathrm{NH}_{4}\right)_{2} \mathrm{SO}_{4}$.
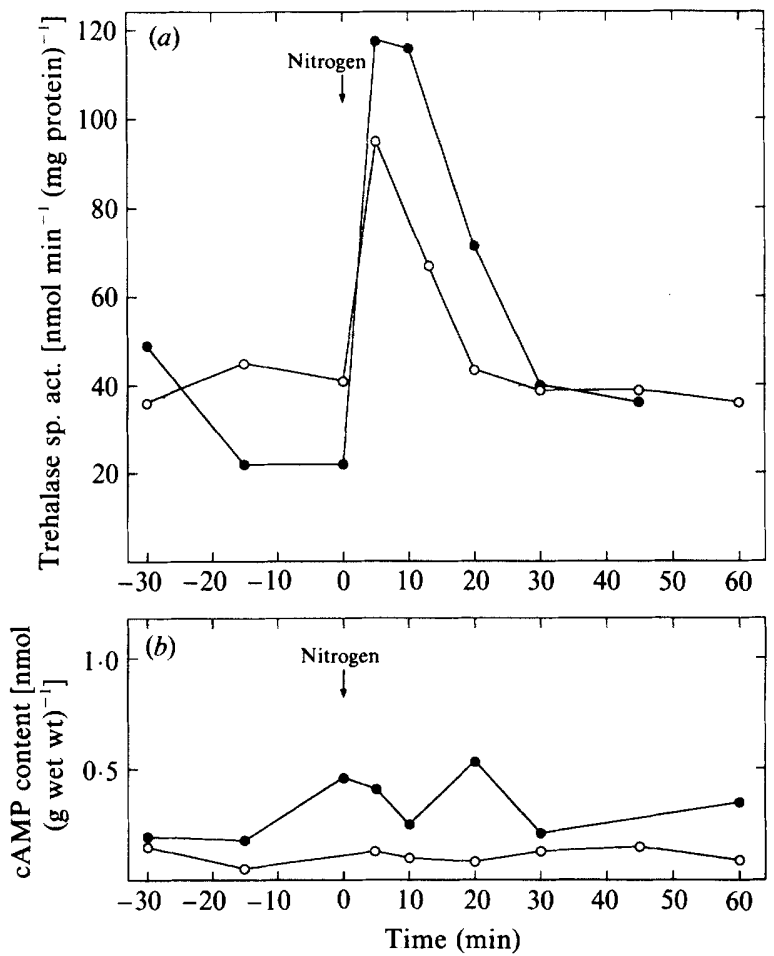

Fig. 6. Trehalase activity (a) and cAMP level (b) upon re-addition of a nitrogen source (10 mM-asparagine + the essential amino acids) to nitrogen-starved cells of the $c d c 25-5$ strain with the $\mathrm{p} R A S 2^{\text {ile } 152}$ plasmid., $24^{\circ} \mathrm{C} ; \mathrm{O}, 37^{\circ} \mathrm{C}$. Starvation and re-addition were carried out in medium containing glucose and Yeast Nitrogen Base without amino acids and without $\left(\mathrm{NH}_{4}\right)_{2} \mathrm{SO}_{4}$.

starvation and re-addition of nutrients on metabolism and its regulation. In addition, the first morphological indication of progression over the start point in yeast cells, i.e. bud formation, occurs much later than the

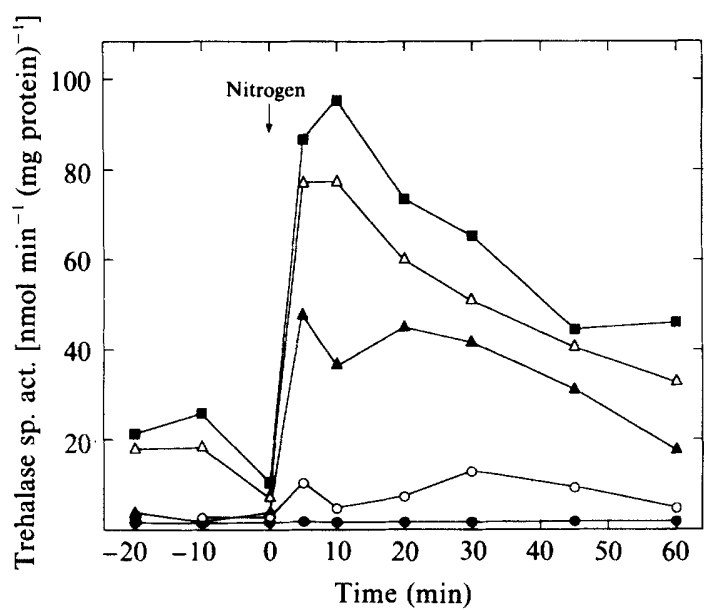

Fig. 7. Nitrogen-source $\left(10 \mathrm{mM}-\mathrm{NH}_{4} \mathrm{Cl}\right)$-induced activation of trehalase at different external glucose concentrations in nitrogen-starved cells of the $c d c 25-5$ strain at the permissive temperature. Glucose concentrations:, $0 \mathrm{mM} ; 0,5 \mathrm{mM} ; \Delta, 20 \mathrm{mM} ; \triangle, 100 \mathrm{~mm} ; \square$, $160 \mathrm{~mm}$. Starvation and re-addition were carried out in synthetic medium.

actual start event and requires many additional processes which are not required for progression over the start point itself. In the present paper, we show that nutrientinduced activation of trehalase might constitute a very convenient marker for studying the mechanisms involved in nutrient-induced progression over the start point of the yeast cell cycle. Rapid activation of trehalase is associated not only with glucose- (review: Thevelein, 1991), but also with nitrogen-, phosphate- and sulphateinduced growth in cells starved for these nutrients (Fig. 2 ), and also with stimulation of growth by addition of a good nitrogen source to cells growing slowly on a poor nitrogen source. The latter is known to be associated with 


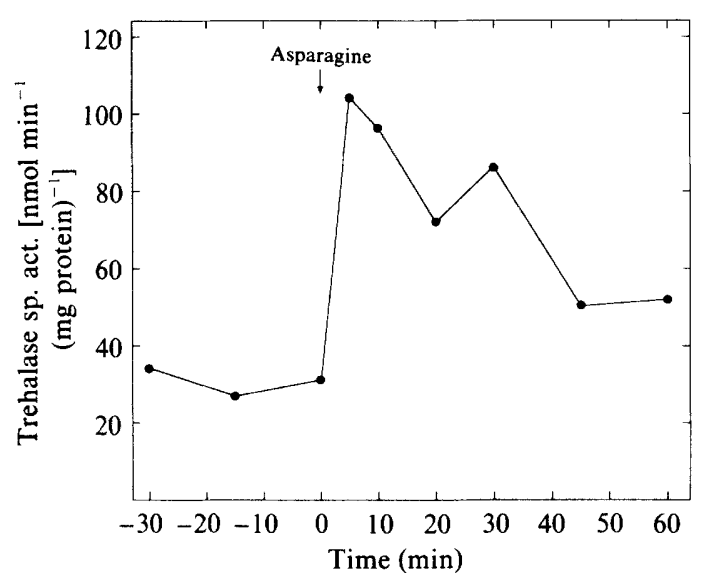

Fig. 8. Asparagine-induced activation of trehalase in yeast cells of the wild-type strain Y55 growing with proline as nitrogen source in a medium (according to Rivin \& Fangman, 1980) containing glucose and Yeast Nitrogen Base (without any other nitrogen source).

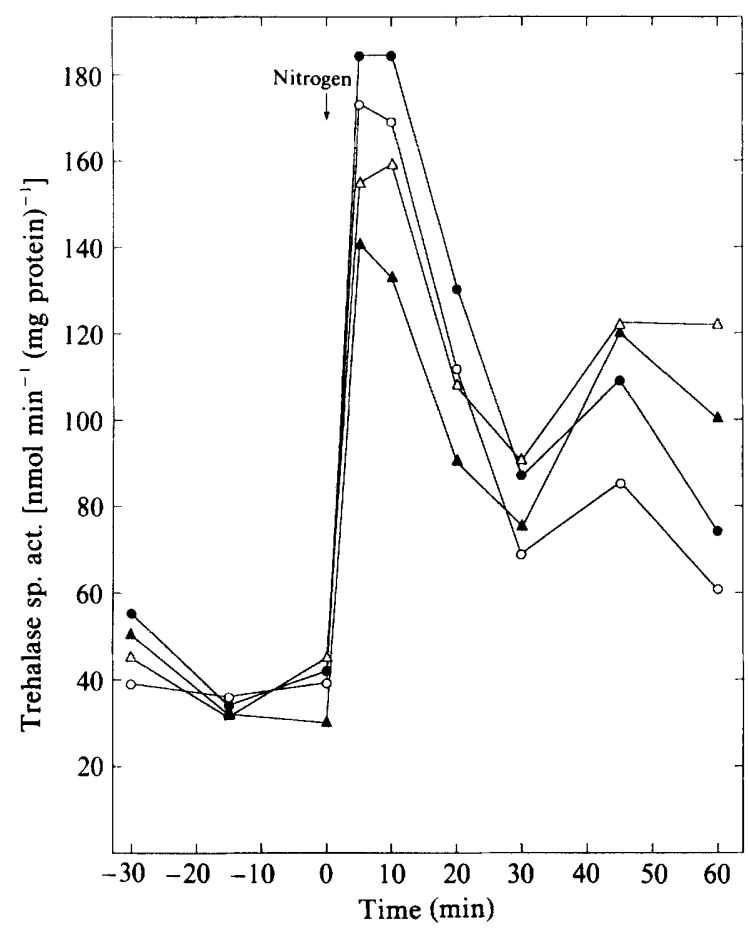

Fig. 9. Asparagine-induced activation of trehalase in nitrogen-starved yeast cells of the wild-type strain Y55 fractionated by elutriation according to cell size. Approximate cell diameters: $0,5-6 \mu \mathrm{m} ; 0,6$ $7 \mu \mathrm{m} ; \Delta, 8-9 \mu \mathrm{m} ; \triangle, 9-10 \mu \mathrm{m}$.

a shortening, specifically of the $G_{1}$ phase of the cell cycle (Pringle \& Hartwell, 1981). In addition, trehalase is known to be regulated by cAMP-dependent protein phosphorylation (review: Thevelein, 1988), for which a crucial role in the control of progression over the start point of the yeast cell cycle is well established (Matsumoto et al., 1985). Hence, both activation of trehalase and progression over the start point of the cell cycle by

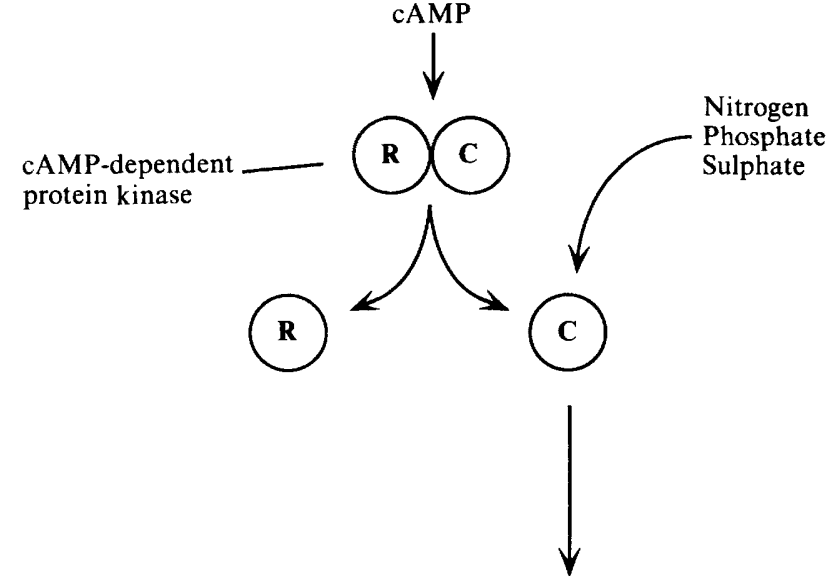

Activation of trehalase Progression over the start point of the cell cycle

Fig. 10. Proposed model of the relationship between nitrogen, phosphate and sulphate availability and the cAMP-cAMP-dependent protein kinase pathway. The three nutrients are suggested to activate the pathway at an intermediate point, i.e. the free catalytic subunits of cAMP-dependent protein kinase.

nutrients might be induced by a common signalling pathway.

Although it is well known that nutrient availability controls progression over the start point and that cAMP is required for this progression, the relationship between the two is not well understood. It has been suggested that nutrients stimulate the progression by increasing cAMP levels (Jacquet \& Camonis, 1985; Dumont et al., 1989; Engelberg et al., 1989; Gibbs \& Marshall, 1989; Malone, 1990) but very little evidence in support of this idea has been reported. We have previously shown that nitrogen source do not elevate the cAMP level (Thevelein \& Beullens, 1985) and this is now clearly confirmed for nitrogen-starved cells too (Fig. 2). Sulphate also has no effect in sulphate-starved cells while the small increase caused by phosphate addition to phosphate-starved cells is difficult to interpret owing to the requirement of ATP metabolism for phosphate. In addition, however, our results show that all three nutrients are able to cause significant activation of trehalase at cAMP levels clearly below the normal cAMP level in wild-type cells (Figs 2 and 3). This makes it very unlikely that cAMP would be involved as second messenger in this nutrient-induced signalling process. On the other hand, in temperaturesensitive mutants for cAMP synthesis, the extent of nutrient-induced activation of trehalase is, in all cases, reduced at the restrictive temperature compared to the permissive temperature, i.e. the presence of a lower cAMP level reduces the extent of trehalase activation. These results support a model in which nutrient-induced signalling depends on a basal cAMP level rather than being mediated by an increase in the cAMP level. We 
have proposed previously a model for nitrogen signalling in which a nitrogen-source-induced pathway was able to activate free (and only free) catalytic subunits of cAMPdependent protein kinase (Thevelein, 1991, 1992) (Fig. 10). Since the total number of free catalytic subunits depends on the CAMP level, nitrogen signalling is, in this model, also dependent on the cAMP level but only in an indirect way, i.e. not by influencing the level of cAMP itself. The results in Figs 2 and 3 are in agreement with this model, not only for nitrogen- but also for phosphateand sulphate-induced signalling. When the temperaturesensitive mutants in cAMP synthesis are incubated at the restrictive temperature, activation of trehalase is observed despite the fact that the cAMP level is very low and therefore the number of free catalytic subunits would be expected to be very low also. This can be explained by assuming an excess of catalytic subunits compared to regulatory subunits. This excess, however, would not provide enough protein kinase activity to trigger progression over the start point of the cell cycle under conditions of cAMP deficiency. The latter would also explain why trehalase activation but no growth is observed under conditions of cAMP deficiency.

The model in which nitrogen sources $(+$ phosphate and sulphate) activate, by an unknown pathway, the free catalytic subunits of cAMP-dependent protein kinase provides an elegant explanation for (1) the fact that starvation for these nutrients causes cell cycle arrest at exactly the same point as cAMP deficiency, although it does not cause cAMP deficiency itself, and (2) the fact that nitrogen-starvation is unable to cause $G_{1}$ arrest in cells with high protein kinase activity, such as those with a deletion of the $B C Y l$ gene encoding the regulatory subunit or cells with an elevated cAMP level (Matsumoto et al., 1983). In this case, kinase activity is constitutively high and cannot be reduced to a subnormal level by nitrogen starvation. In our model, the precise role of the RAS-adenylate cyclase system is to provide and to control the possibility of synergistic stimulation of cAMP-dependent protein kinase by a nutrient-induced signalling pathway. This possibility is shut-off if the cAMP level drops too low. At normal cAMP levels, it is limited by the available level of free catalytic subunits. In extreme cases (or maybe only in mutants), the cAMP level increases so much that all catalytic subunits are set free and nutrient-induced synergistic stimulation becomes irrelevant.

A crucial point in the proposed model is that nitrogen sources and the other nutrients act on cAMP-dependent protein kinase and not on another protein kinase. Recent results from our laboratory on nitrogen-induced activation of trehalase in yeast mutants that have very different levels of cAMP-dependent protein kinase activity clearly support this idea (P. Durnez, unpublished results). In the present paper, we have tried to establish firmly that nitrogen sources in particular do not activate trehalase by enhancing the cAMP level. Despite this, trehalase activation by nitrogen sources is probably mediated by cAMP-dependent protein kinase (unpublished). Future studies will be directed towards elucidation of this novel nitrogen-induced signalling pathway.

In the present paper, we also show that the glucoseconcentration dependence of nitrogen-induced activation of trehalase is very similar to that for activation of the RAS-adenylate cyclase pathway (Fig. 7; Beullens et al., 1988). This might indicate that the glucose-sensing system involved in the latter is also required for nitrogeninduced activation of trehalase. Recent results from our laboratory support the idea that all glucose-induced regulatory effects in yeast are dependent on the same glucose-sensing system (Thevelein, 1992). The glucose requirement of the nitrogen signalling pathway creates the interesting possibility that the pathway involved could serve as a sensor for the presence both of glucose and of nitrogen and possibly also of phosphate and sulphate. This would provide a logical explanation as to why starvation for these nutrients causes arrest at the same point in the $G_{1}$ phase of the cell cycle.

The results in Fig. 2 for the $c d c 25-5$ mutant show a partial activation of trehalase at the restrictive temperature that is not associated with any mobilization of trehalose. This might be explained by trehalose biosynthesis counteracting the effect of trehalase. Recently, François et al. (1991) have shown that nitrogen strongly stimulates a glucose-dependent inactivation of trehalose6-phosphate synthase and phosphatase. If this inactivation is reduced in the $c d c 25-5$ mutant at the restrictive temperature, the balance of trehalose synthesis and hydrolysis could easily be shifted in favour of the former.

We wish to thank M. Jacquet (Orsay, France) and M. Wigler (Cold Spring Harbor, NY, USA) for provision of yeast strains. We are also grateful to Gist-Brocades for isolation of monoclonal antibodies against our purified trehalase preparation. P. Durnez gratefully acknowledges receipt of a fellowship from the Instituut voor aanmoediging van het Wetenschappelijk Onderzoek in Nijverheid en Landbouw. This research was supported by grants from the Belgian National Fund for Scientific Research (FGWO, Kom op tegen Kanker), the Belgian National Lottery and the Research Fund of the K.U. Leuven.

\section{References}

Becher dos Passos, J. B., Vanhalewyn, M., Brandão, R. L., Castro, I. M., Nicoli, J. R. \& Thevelein, J. M. (1992). Glucose-induced activation of plasma membrane $\mathrm{H}^{+}$-ATPase in mutants of the yeast Saccharomyces cerevisiae affected in cAMP metabolism, cAMPdependent protein phosphorylation and the initiation of glycolysis. Biochimica et Biophysica Acta 1136, 57-67. 
Beullens, M., Mbonyi, K., Geerts, L., Gladines, D., Detremerie, K., JANS, A. W. H. \& Thevelein, J. M. (1988). Studies on the mechanism of the glucose-induced cAMP-signal in glycolysis- and glucose repression-mutants of the yeast Saccharomyces cerevisiae. European Journal of Biochemistry 172, 227-231.

BROACH, J. R. \& DESCHENES, R. J. (1990). The function of RAS genes in Saccharomyces cerevisiae. Advances in Cancer Research 54, 79-139.

CAMONIS, J. H. \& JACQUeT, M. (1988). A new RAS mutation that suppresses the $C D C 25$ gene requirement for growth of Saccharomyces cerevisiae. Molecular and Cellular Biology 8, 2980-2983.

Camonis, J. H., Kalekine, M., Gondre, B., Garreau, H., BoyMARCOTTE, E. \& JACQUET, M. (1986). Characterization, cloning and sequence analysis of the $C D C 25$ gene which controls the cyclic AMP level of Saccharomyces cerevisiae. EMBO Journal 5, 375-380.

Dumont, J. E., Jauniaux, J. C. \& Roger, P. P. (1989). The cyclic AMP-mediated stimulation of cell proliferation. Trends in Biochemical Sciences 14, 67-71.

Engelberg, D., Perlman, R. \& Levitzki, A. (1989). Transmembrane signalling in Saccharomyces cerevisiae. Cellular Signalling 1, 1-7.

François, J., Villanueva, M. E. \& Hers, H.-G. (1988). The control of glycogen metabolism in yeast. 1. Interconversion in vivo of glycogen synthase and glycogen phosphorylase induced by glucose, a nitrogen source or uncoupler. European Journal of Biochemistry 174, 551-559.

Françols, J., NeVes, M.-J. \& Hers, H.-G. (1991). The control of trehalose biosynthesis in Saccharomyces cerevisiae: evidence for a catabolite inactivation and repression of trehalose-6-phosphate synthase and trehalose-6-phosphate phosphatase. Yeast 7, 575-587.

GibBS, J. B. \& MarShall, M. S. (1989). The ras oncogene - an important regulatory element in lower eucaryotic organisms. Microbiological Reviews 53, 171-185.

JACQUET, M. \& CAMONIS, J. (1985). Contrôle du cycle de division cellulaire et de la sporulation chez Saccharomyces cerevisiae par le système de l'AMP cyclique. Biochimie 67, 35-43.

Johnston, G. C., Pringle, J. R. \& Hartwell, L. H. (1977). Coordination of growth with cell division in the yeast Saccharomyces cerevisiae. Experimental Cell Research 105, 79-98.

Lillie, S. H. \& Pringle, J. R. (1980). Reserve carbohydrate metabolism in Saccharomyces cerevisiae. Response to nutrient limitation. Journal of Bacteriology 143, 1384-1394.

MALONE, R. E. (1990). Dual regulation of meiosis in yeast. Cell 61, 375 378.

Matsumoto, K., Uno, I. \& Ishikawa, T. (1983). Control of cell division in Saccharomyces cerevisiae mutants defective in adenylate cyclase and cAMP-dependent protein kinase. Experimental Cell Research 146, 151-161.

Matsumoto, K., Uno, I. \& Ishikawa, T. (1985). Genetic analysis of the role of cAMP in yeast. Yeast 1, 15-24.

Mbonyi, K., Beullens, M., Detremerie, K., Geerts, L. \& TheveLEIN, J. M. (1988). Requirement of one functional RAS gene and inability of an oncogenic ras variant to mediate the glucose-induced cyclic AMP signal in the yeast Saccharomyces cerevisiae. Molecular and Cellular Biology 8, 3051-3057.

Pringle, J. R. \& Hartwell, L. H. (1981). The Saccharomyces cerevisiae cell cycle. In The Molecular Biology of the Yeast Saccharomyces. Metabolism and Gene Expression, pp. 97-142. Edited by J. N. Strathern, E. W. Jones \& J. R. Broach. Cold Spring Harbor, NY: Cold Spring Harbor Laboratory.
Rivin, C. J. \& Fangman, W. L. (1980). Cell-cycle phase expansion in nitrogen-limited cultures of Saccharomyces cerevisiae. Journal of Cell Biology 85, 96-107.

Sherman, F., Fink, G. R. \& Hicks, J. B. (1986). Laboratory Course Manual for Methods in Yeast Genetics. Cold Spring Harbor, NY: Cold Spring Harbor Laboratory.

Thevelein, J. M. (1984a). Cyclic-AMP content and trehalase activation in vegetative cells and ascospores of yeast. Archives of Microbiology 138, 64-67.

Thevelein, J. M. (1984b). Regulation of trehalose mobilization in fungi. Microbiological Reviews 48, 42-59.

Thevelein, J. M. (1988). Regulation of trehalase activity by phosphorylation-dephosphorylation during developmental transitions in fungi. Experimental Mycology 12, 1-12.

THEvelein, J. M. (1991). Fermentable sugars and intracellular acidification as specific activators of the RAS-adenylate cyclase signalling pathway in yeast : the relationship to nutrient-induced cell cycle control. Molecular Microbiology 5, 1301-1307.

Thevelein, J. M. (1992). The RAS-adenylate cyclase pathway and cell cycle control in Saccharomyces cerevisiae. Antonie van Leeuwenhoek, Journal of Microbiology. Special Issue: Molecular Biology of Yeasts. Edited by L. Grivell 62, 109-130.

Thevelein, J. M. \& Beullens, M. (1985). Cyclic AMP and the stimulation of trehalase activity in the yeast Saccharomyces cerevisiae by carbon sources, nitrogen sources and inhibitors of protein synthesis. Journal of General Microbiology 131, 3199-3209.

Thevelein, J. M., Van Laere, A. J., Beullens, M., Van Assche, J. A. \& CARLIER, A. R. (1983). Glucose-induced trehalase activation and trehalose mobilization during early germination of Phycomyces blakesleeanus spores. Journal of General Microbiology 129, 719726.

Thevelein, J. M., Beullens, M., Honshoven, F., Hoebeeck, G., Detremerie, K., Den Hollander, J. A. \& Jans, A. W. H. (1987). Regulation of the cAMP level in the yeast Saccharomyces cerevisiae: intracellular $\mathrm{pH}$ and the effect of membrane depolarizing compounds. Journal of General Microbiology 133, 2191-2196.

Toda, T., Uno, I., Ishikawa, T., Powers, S., Kataoka, T., Broek, D., Cameron, S., Broach, J., Matsumoto, K. \& Wigler, M. (1985). In yeast, Ras proteins are controlling elements of adenylate cyclase. Cell 40, 27-36

Trevelyan, W. E. \& Harrison, J. S. (1956). Studies on yeast metabolism. V. The trehalose content of baker's yeast during anaerobic fermentation. Biochemical Journal 62, 177-183.

Van Aelst, L., Boy-Marcotte, E., Camonis, J. H., Thevelein, J. M. \& JACQUET, M. (1990). The C-terminal part of the CDC25 gene product plays a key role in signal transduction in the glucose-induced modulation of cAMP level in Saccharomyces cerevisiae. European Journal of Biochemistry 193, 675-680.

VAN Aelst, L., Jans, A. W. H. \& Thevelein, J. M. (1991). Involvement of the $C D C 25$ gene product in the signal transmission pathway of the glucose-induced RAS-mediated cAMP signal in the yeast Saccharomyces cerevisiae. Journal of General Microbiology 137, 341-349.

VAN Der PlaAT, J. B. (1974). Cyclic 3',5'-adenosine monophosphate stimulates trehalose degradation in baker's yeast. Biochemical and Biophysical Research Communications 56, 580-587. 